\title{
Prevalence and predictors of post-stroke spasticity and its impact on daily living and quality of life
}

\author{
Michał J. Schinwelski ${ }^{1,2,3}$, Emilia J. Sitek ${ }^{1,2}$, Piotr Wąż ${ }^{4}$ Jarosław W. Sławek ${ }^{1,2}$ \\ ${ }^{1}$ Neurology Department, St. Adalbert Hospital, Copernicus, Gdansk, Poland \\ ${ }^{2}$ Neurological and Psychiatric Nursing Department, Faculty of Health Sciences, Medical University of Gdansk, Poland \\ ${ }^{3}$ Specjalistyczny Gabinet Lekarski Poradnia Neurologiczna Michał Schinwelski, Tczew, Poland \\ ${ }^{4}$ Department of Nuclear Medicine, Faculty of Health Sciences, Medical University of Gdansk, Poland
}

\section{ABSTRACT}

Background and aims. The present study aimed to assess the frequency of spasticity in a single-centre cohort of stroke patients in a one-year follow-up, its predictors, and its impact on the activities of daily living (ADL) and health-related quality of life (HRQoL).

Material and methods. A group of 121 consecutive patients with hemiparesis (aged $73 \pm 11$ years) was selected for further observation, out of 381 Stroke Department patients during one year. At three follow-up assessments three, six and 12 months after stroke, muscle tone and muscle weakness were rated using Modified Ashworth Scale (MAS) and Medical Research Council (MRC); Activities of Daily Living (ADL) and Health Related Quality of Life (HRQoL) were evaluated using the Barthel Index (BI), Modified Rankin Scale (mRS) and an SF-36 questionnaire.

Results. Fifty five of 121 (45\%) patients after three months had developed spasticity (MAS $\geq 1$ ), and in 19 of the 121 (15\%) this spasticity was severe. After one year, 33/94 (35\%) patients showed spasticity, and in 19/94 (20\%) it was severe. Baseline muscle weakness (MRC), stroke severity as measured by the National Institutes of Health Stroke Scale (NIHSS), and greater disability (BI), were the most significant predictors of persistent post-stroke spasticity. Patients with spasticity had worse HRQoL in terms of their physical functioning, role limitations, physical pain, and vitality.

Conclusion. Spasticity, which affects a significant proportion of stroke survivors, was present in 35\% of our patients at 12 months after stroke. It has a major impact on both ADL and HRQoL. Severe disability and muscle weakness are the most important predictors of persistent post-stroke spasticity.

Key words: spasticity, stroke, epidemiology, quality of life, predictors, hemiplegia

(Neurol Neurochir Pol 2019; 53 (6): 449-457)

\section{Introduction}

Stroke is a leading cause of disability among adults. Upper motor neuron syndrome with accompanying spasticity is its major clinical presentation $[1,2]$. Spasticity is not only one of the major factors contributing to the handicap, but also one that can be treated pharmacologically [3]. According to European and Asian studies, the prevalence of post-stroke spasticity ranges from $7 \%$ to $38 \%$ in up to 18 -month observations [4, 5]. In two German and Swedish studies in patients with initial limb paresis after stroke, the prevalence of spasticity was $42 \%$ and $46 \%$ at six and 12 months respectively [6,7]. The literature focusing on the impact of spasticity on the activities of daily living (ADL) and health-related quality of life (HRQoL) is limited [8]. The present study aimed to indicate prospectively the frequency of spasticity, its impact on ADL and HRQoL, and to identify predictors of persistent spasticity in a single-centre cohort of stroke patients.

\section{Subjects and methods}

Subjects

All patients admitted to the Stroke Unit at the Neurology Department were consecutively recruited over a 12-month 
period. This Neurology Department is exclusively responsible for the neurological care of a region with around 200,000 inhabitants, and all stroke patients without any selection were admitted. All adult stroke patients with limb paresis at discharge were invited to participate in the study. The presence of other neurological diseases that affect muscle tone and treatment with botulinum toxin were the only two exclusion criteria. Medical records of a total of 381 patients were screened, and of these 121 patients were selected and assessed three months after stroke onset. Of the 121 study participants, 99 were reassessed at six months and 94 at 12 months after stroke (see Fig.1). The patients' age averaged 73.74 years ( \pm 11.45 ; range $23-97$ ). Females were more prevalent, comprising 66 (54.5\%). Our selected group did not differ in terms of age and sex from the remaining stroke patients of the entire cohort $(n=381)$. Clinical characteristics of the cohort included in the study are set out in Table 1.

\section{Muscle tone assessment}

Spasticity was assessed with the use of the Modified Ashworth Scale (MAS) [9], grading the resistance of a relaxed limb to rapid passive stretching over six stages. In the present study, arm adductors, elbow flexors/extensors, wrist flexors/ extensors, and finger flexors were examined with the patient in a sitting position. In the lower limbs, hip adductors, knee flexors/extensors, and plantar flexors/extensors were tested in patients in a supine position. The MAS is considered to be fairly reliable [10] and correlates to more objective electrophysiological tests [11]. Three degrees of spasticity in any of the muscle groups were defined: any (MAS $\geq 1$ ), moderate (MAS $\geq 2$ ), and severe (MAS $\geq 3$ ). All assessments were performed by the same physician (M.S.).

\section{Stroke severity and motor assessments}

Initially in the acute phase of stroke, patients were assessed with the National Institutes of Health Stroke Scale (NIHSS), which is a 46-point scale. This is considered reliable and valid as well as quick and easy to use [12]. At discharge from the Neurology department, and three, six and 12 months after stroke, muscle strength was assessed by Medical Research Council (MRC) (grades 0 to 5) for all muscle groups that were also tested for muscle tone [13].

\section{Activities of daily living and quality of life}

Disability related to activity performance and participation was assessed with the use of the Modified Rankin Scale (mRS) and the Barthel Index (BI) which are considered to be reliable, valid and sensitive [14, 15]. HRQoL was assessed by the Short Form 36 Health Survey Questionnaire (SF-36) v.2 [16], which consists of 36 items grouped into the following eight health scales: physical functioning, role limitations due to physical problems, physical pain, general health perceptions, vitality, social functioning, role limitations due to emotional problems, and mental health. This is considered to be a reliable and valid measure of physical-health-related and mental-health-related quality of life after stroke [17]. Eighty patients were able to complete the SF-36 form.

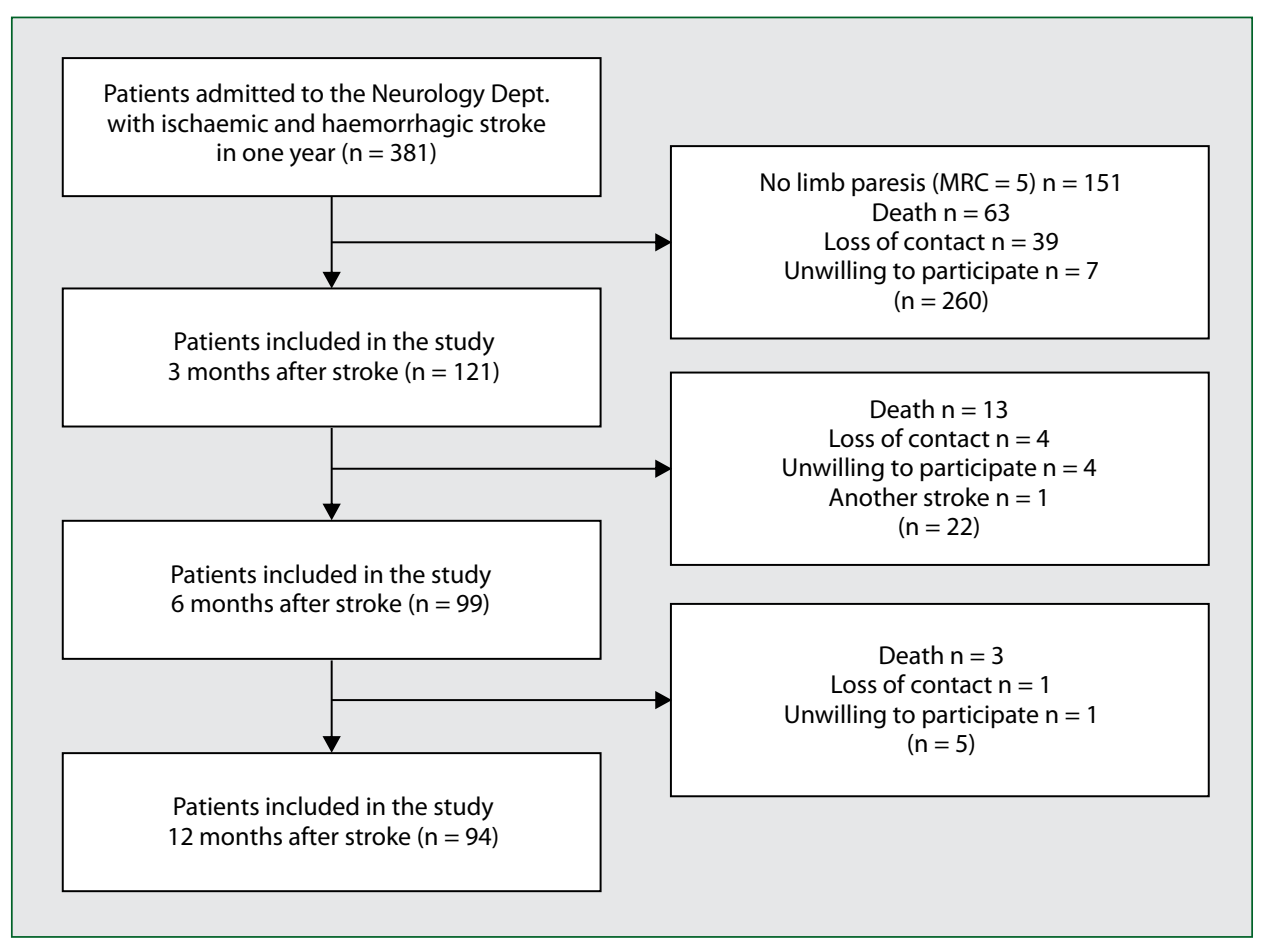

Figure 1. Detailed recruitment schedule 
Table 1. Clinical and demographic characteristics of study participants

\begin{tabular}{|c|c|c|c|c|c|c|c|}
\hline Variable & Number & Percentage (\%) & Variable & Mean & Median & SD & Min.-Max. \\
\hline Sex: & & & Age & 73.74 & 75.00 & 11.45 & $23-97$ \\
\hline Female & 66 & 54.5 & NIHSS admisson & 9.79 & 8.00 & 6.90 & $1-33$ \\
\hline Male & 55 & 45.5 & NIHSS discharge & 6.63 & 4.00 & 6.27 & $0-32$ \\
\hline Stroke aetiology: & & & Bl discharge & 54.95 & 65.00 & 39.03 & $0-100$ \\
\hline Ischaemic & 112 & 92.6 & mRS discharge & 3.07 & 3.00 & 1.4 & $0-5$ \\
\hline Haemorrhagic & 9 & 7.4 & & & & & \\
\hline \multicolumn{8}{|l|}{ Localisation: } \\
\hline Right hemisphere & 59 & 48.8 & & & & & \\
\hline Left hemisphere & 54 & 44.6 & & & & & \\
\hline Brainstem & 6 & 5.0 & & & & & \\
\hline Bilateral & 2 & 1.7 & & & & & \\
\hline \multicolumn{8}{|l|}{ Risk factors: } \\
\hline History of stroke & 23 & 19.2 & & & & & \\
\hline Hypertension & 100 & 83 & & & & & \\
\hline Atrial fibrillation & 39 & 32.1 & & & & & \\
\hline Dyslipidemia & 55 & 45.5 & & & & & \\
\hline Diabetes & 33 & 27.1 & & & & & \\
\hline Coronary disease & 39 & 32.1 & & & & & \\
\hline Thrombolytic therapy & 7 & 5.7 & & & & & \\
\hline Carotid arterty stenosis & 23 & 19.1 & & & & & \\
\hline Smoking & 14 & 11.5 & & & & & \\
\hline Alcohol abuse & 3 & 2.5 & & & & & \\
\hline
\end{tabular}

\section{Predictors of spasticity}

Data obtained during hospitalisation such as muscle weakness (MRC), disability (mRS, BI), stroke severity (NIHSS), aetiology and location of stroke, aphasia, dysarthria, presence of hypertension, atrial fibrillation, dyslipidemia, diabetes, coronary heart disease, previous stroke, history of smoking, alcohol abuse, and intravenous thrombolytic therapy were analysed to determine the risk factors for spasticity.

\section{Statistical analysis}

The Shapiro-Wilk test and Brown-Forsythe tests were used to test the normality of distribution and the homogeneity of variance respectively. Intergroup differences were tested with the $\chi^{2}$ test for categorical variables and Mann-Whitney U tests for continuous variables. The associations between MAS and the MRC, BI, NIHSS, mRS were analysed with the use of Spearman rank-order correlation coefficient. Multivariate backward stepwise logistic regression analysis was used to predict the presence of (a) any spasticity, (b) moderate spasticity and (c) severe spasticity at three, six and 12 months post-stroke either in any of the limbs or separately for the upper limbs and the lower limbs. A two-stage approach was used to build regression models. Initially, univariate regression analyses were used to screen for variables likely to be associated with spasticity at each time point $(\mathrm{p}<0.10)$. Variables such as age, sex, left / right sided weakness, thrombolysis, history of previous stroke, NIHSS score at discharge, BI, MRC total score (global or for upper / lower limbs respectively) at the first and at the second assessment were considered as possible predictors of spasticity. Also, correlation analysis was performed, as in each of the analyses the correlation coefficients between MRC total score at baseline and at three months were higher than 0.80 ; only baseline score (easier to measure from the clinical point of view) was considered for further analyses. Then, possible interactions among the selected variables were identified. Finally, the variables identified in univariate analyses and their interactions were entered into a multivariate backward stepwise regression model.

The results are presented with nonstandardised coefficients, p values, and odds ratios with $95 \%$ confidence intervals ( $95 \%$ CIs). Significance level was set at $\mathrm{p}<0.05$, unless specified otherwise (in the case of exploratory analyses). Nagelkerke R2 was used as a measure of goodness of fit. All statistical analyses were performed using Microsoft Excel 2010, IBM SPSS statistics 23.0, R-project ver. 3.0.2 and STATISTICA Statsoft Poland v12, including Plus Set 3.0. 
Table 2. Number of patients with spasticity in both upper and lower limbs

$\begin{array}{ccccc}\text { Months after stroke } & \text { No. of patients } & \text { Frequency N (\%) } \\ & & \text { MAS } \geq \mathbf{1} & \text { MAS } \geq \mathbf{2} & \text { MAS } \geq \mathbf{3} \\ 3 & 121 & 55(45) & 45(37) & 19(15) \\ 6 & 99 & 41(41) & 35(35) & 23(23) \\ 12 & 94 & 33(35) & 29(31) & 19(20)\end{array}$

Number of patients with spasticity in upper limbs

\begin{tabular}{cccc} 
Months after stroke & No. of patients & \multicolumn{2}{c}{ Frequency N (\%) } \\
& & MAS $\geq \mathbf{1}$ & MAS $\geq 2$ \\
3 & 121 & $55(45)$ & $43(35)$ \\
6 & 99 & $41(41)$ & $34(34)$ \\
12 & 94 & $33(35)$ & $23(23)$
\end{tabular}

Number of patients with spasticity in lower limbs

\begin{tabular}{|c|c|c|c|c|}
\hline \multirow[t]{2}{*}{ Months after stroke } & \multirow[t]{2}{*}{ No. of patients } & \multicolumn{3}{|c|}{ Frequency N (\%) } \\
\hline & & MAS $\geq 1$ & MAS $\geq 2$ & MAS $\geq 3$ \\
\hline 3 & 121 & $39(32)$ & $31(26)$ & $14(11)$ \\
\hline 6 & 99 & $31(31)$ & $24(24)$ & $12(12)$ \\
\hline 12 & 94 & $25(27)$ & $18(19)$ & $14(15)$ \\
\hline
\end{tabular}

MAS - Modified Ashworth Scale

\section{Results}

Prevalence of spasticity

The prevalence of different degrees of spasticity is set out in Table 2. Generally, frequency of spasticity decreased between three and 12 months post stroke from $45 \%$ to $35 \%$ in the upper limbs (UL) and from $32 \%$ to $27 \%$ in the lower limbs (LL).

\section{Distribution of spasticity}

In the UL, increased muscle tone was observed most frequently in elbow flexors/extensors, followed by shoulder adductors, wrist flexors/extensors, and finally in fingers in the 12-month observation. The distribution was variable over time, and distal spasticity (fingers, wrist) was more pronounced after 12 months. Spasticity did not differ between proximal and distal muscle groups in the LL, but over time more severe spasticity in plantar flexors was observed. The distribution of different muscle groups within the UL and the LL is presented in Figure 2.

Impact of spasticity on the activities of daily living and health related quality of life

Spastic patients were more disabled as measured by mRS and BI, (Tab. 3) and these differences persisted over time.

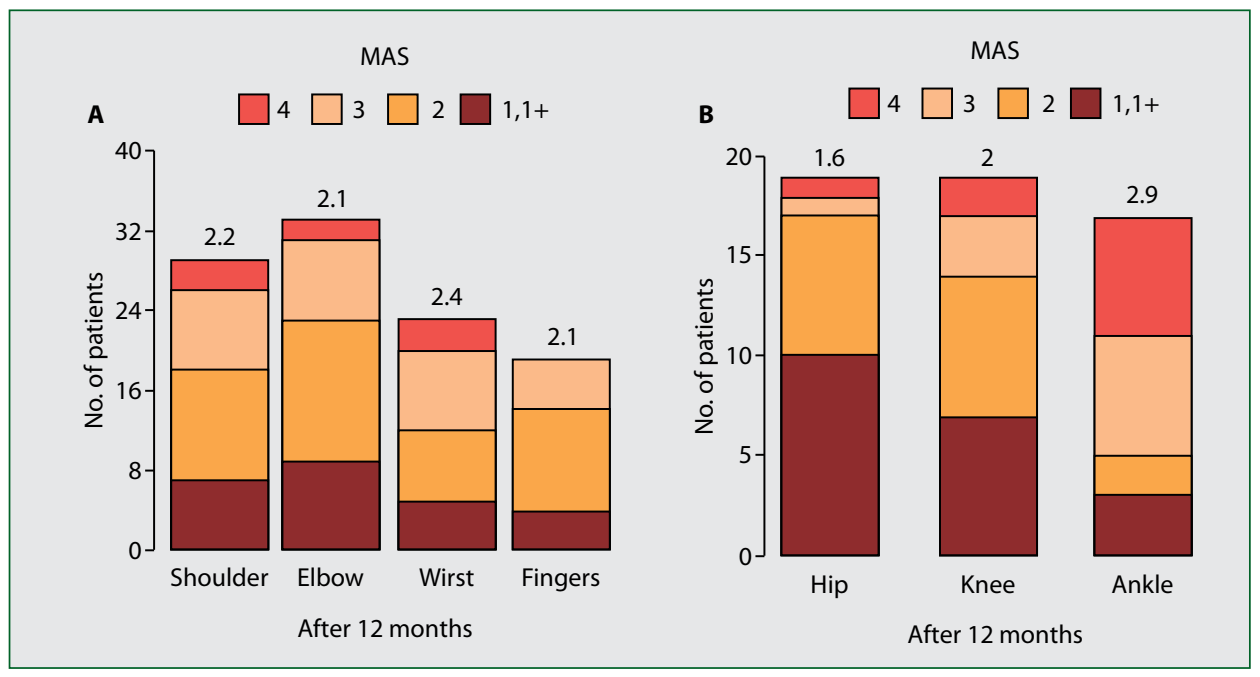

Figure 2. Severity and distribution of spasticity in different muscle groups in upper and lower limbs after 12 months MAS - Modified Ashworth Scale 
Table 3. Comparisons between spastic and non-spastic patients with reference to disability as measured by $\mathrm{mRS}$ and $\mathrm{BI}$

\begin{tabular}{|c|c|c|c|c|c|}
\hline \multicolumn{6}{|c|}{ Modified Rankin Scale } \\
\hline \multirow{2}{*}{$\begin{array}{l}\text { Months after } \\
\text { stroke }\end{array}$} & \multicolumn{2}{|c|}{ Patients with spasticity } & \multicolumn{2}{|c|}{ Patients without spasticity } & \multirow[t]{2}{*}{ P-value } \\
\hline & Mean & Median & Mean & Median & \\
\hline 3 & 3.2 & 3 & 2.27 & 2 & 0.0006 \\
\hline 6 & 3.17 & 3 & 1.7 & 1 & 0.0000004 \\
\hline 12 & 3.21 & 3 & 1.65 & 1 & 0.00000004 \\
\hline \multicolumn{6}{|c|}{ Barthel Index } \\
\hline \multirow{2}{*}{$\begin{array}{c}\text { Months after } \\
\text { stroke }\end{array}$} & \multicolumn{2}{|c|}{ Patients with spasticity } & \multicolumn{2}{|c|}{ Patients without spasticity } & \multirow[t]{2}{*}{ P-value } \\
\hline & Mean & Median & Mean & Median & \\
\hline 3 & 60.27 & 80 & 70.08 & 92.05 & 0.023 \\
\hline 6 & 61.71 & 80 & 85.09 & 100 & 0.00007 \\
\hline 12 & 62.42 & 80 & 86.07 & 100 & 0.00001 \\
\hline
\end{tabular}

Spasticity correlated strongly with the degree of muscle weakness (rho from -0.418 to $-0.933, \mathrm{p}<0.001$ ) and hence also correlated significantly with mRS (rho from 0.379 to 0.582 , $\mathrm{p}<0.001$ ) and BI (rho from -0.279 to $-0.482, \mathrm{p}<0.01$ ) scores.

In terms of HRQoL, those patients without spasticity were less impaired in terms of physical functioning, physical and emotional role limitations, physical pain, and vitality subscales of the SF-36 scale (Fig. 3). Additionally, the presence and degree of spasticity significantly correlated with all mentioned SF-36 subscale scores (rho from -0.280 to $-0.517, \mathrm{p}<0.05$ ).

\section{Predictors of spasticity 12 months after stroke}

In almost all of the models (apart from the one predicting LL spasticity at 12 months), MRC total score was a significant predictor of spasticity. In all models predicting spasticity at three months, and in the model predicting LL spasticity at 12 months, BI was also significant. Of note, NIHSS was a predictor only of LL spasticity, both at three and 12 months. Another significant predictor of spasticity was previous stroke history (for LL spasticity). In none of the analyses were age, sex, side of symptoms, or thrombolytic therapy identified as significant independent factors predicting spasticity.

The results of multivariate logistic regression are set out in Table 4.

\section{Discussion}

This is the first East European prospective study on the prevalence of spasticity. Spasticity was present in 45\%, 41\% and $35 \%$ of initially paretic patients at three, six and 12 months after stroke respectively. The incidence of spasticity varies across the studies, with the lowest in Korean [5] and Swedish studies [18-20] from $7 \%$ at 12 months (Korean), 18\% after one week up to $21 \%$ at 18 months (Swedish), moderate (36-38\%) in two British studies [21, 22] in 12-month observations, and the highest ( $42 \%$ and $46 \%)$ in a German study [6] and a recent Swedish study [7] after six and 12 months. The discrepancies between studies may result from different methods and definitions. The frequency of variously defined 'severe' spasticity ranged from $6 \%$ in Lundström et al. [20], which defined severe spasticity as "spasticity having such an impact that intervention, e.g. intensive physiotherapy, orthoses or pharmacological treatment, should be offered" to $15 \%, 21 \%$, and $29 \%$ with the definition of severe spasticity measured as MAS $\geq 3$, Tone Assessment Scale (TAS) $\geq 2$ or MAS $\geq 2$ in studies by Urban et al. [6], Watkins et al. [21] and Opheim et al. [7]. A descriptive definition of spasticity without referring to cut-offs on clinimetric scales may lower the number of patients with spasticity.

Contrary to previous reports, the prevalence of any spasticity (MAS $\geq 1$ ) in our study decreased in 12 months of observation. This could be explained by a relatively small but noticeable drop-out rate throughout the study, and the transfer of patients with any spasticity (MAS $\geq 1$ ) measured only in one joint into the group without spasticity. This transfer is possibly due to physiotherapy within the first year after stroke. A similar observation was found in Sommerfeld et al.s [18] study, with a lower rate of spasticity after three months compared to the first weeks after stroke.

The established number of patients developing spasticity after three months seems the most valuable finding from the practical point of view. At this time point, the neural component is gradually replaced by a biomechanical one, which means that rehabilitation and pharmacological therapy, e.g. with botulinum toxin injections, become less effective [23].

Our study design, with its recruitment of consecutive patients from one inpatient neurological centre, is similar to that of the majority of other studies $[6,7,18-20]$ and makes it possible to assess the real prevalence of spasticity. Additionally, the assessment of muscle tone by the same physician throughout the study eliminated potential inter-rater variability.

In our study, $19 \%$ of patients had a history of previous stroke, while in a British study [21] such patients constituted $34 \%$ of the study group. The inclusion of cases with a previous history of stroke was important because the number of such 


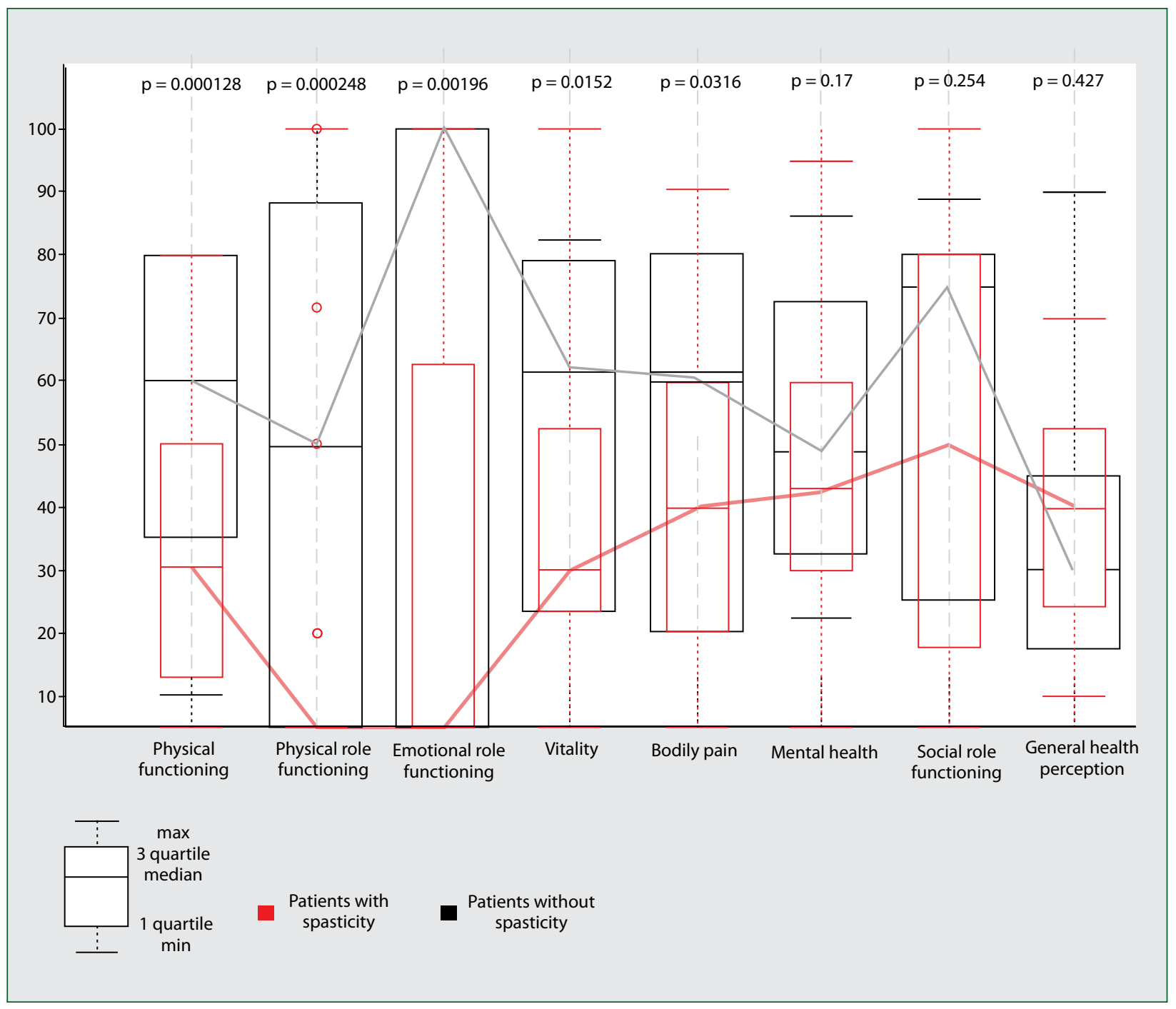

Figure 3. Health-related quality of life in hemiparetic patients with and without spasticity according to eight domains of SF-36 scale

patients being seen in stroke units is increasing, and a second stroke may increase the risk of spasticity and influence its frequency [21]. Of note, in our cohort it was one of the significant spasticity risk factors for lower limb spasticity.

In our study, the frequency of spasticity was $10 \%$ higher in the UL than in the LL, which may result from the greater supraspinal control in UL [26]. Spasticity was most frequent in elbow flexors, arm adductors, and wrist and finger flexors, in that order. In the lower limbs, knee flexors and extensors were most commonly affected. The distribution of spasticity was rather stable, but the severity of spasticity increased distally in both extremities over time. These results confirm those of other studies $[6,27]$ that have found spasticity is common in the anti-gravity muscles, and significantly increases over time. This may be explained initially by neural changes, i.e. increased tonic stretch reflexes, followed later by intrinsic muscle changes. Additionally, more severe spasticity in distal parts of extremities could be associated with their larger cortical representations and long-lasting supraspinal mechanisms of spasticity evolution related to brain plasticity following limb disuse [28].

All of the cited studies [6, 7, 18-22] have found a relationship between spasticity and a worse functional outcome. ADL has been assessed using various methods (e.g. BI, mRS, Brigitta Lindmark, Nine Hole Peg Test, Rivermead Mobility Index, Get Up and Go test), but BI was the most frequently used outcome measure. Similarly, in our study significant associations between severity of spasticity and functioning as measured by BI and mRS were found. As in Swedish studies $[18,19]$ the strength of these associations increased during the 12-month observation. Considering that paresis is usually stable at 12 months, it is presumably spasticity that causes deterioration in functioning [29]. Thus, spasticity should be managed as early as possible.

Stroke survivors had a lower QoL than age-matched controls in $7 / 8$ domains (excluding pain) $[19,30]$. However, 
Table 4. Predictors of post-stroke spasticity in any limb / upper limbs / lower limbs at three, six and 12 months: results of multivariate logistic regression analysis

\begin{tabular}{|c|c|c|c|c|c|c|c|}
\hline \multirow[t]{2}{*}{ Months after stroke } & \multirow[t]{2}{*}{ Predictors of MAS $\geq 1$} & \multirow{2}{*}{$\begin{array}{l}\text { Unstandardised } \\
\text { coefficient }\end{array}$} & \multirow[t]{2}{*}{ P-value } & \multirow[t]{2}{*}{ OR } & \multicolumn{2}{|c|}{$95 \% \mathrm{Cl}$} & \multirow[t]{2}{*}{ Nagelkerke $\mathbf{R}^{2}$} \\
\hline & & & & & Lower & Upper & \\
\hline \multirow[t]{2}{*}{ At 3 months } & $\mathrm{BI}$ & 0.137 & 0.001 & 1.147 & 1.060 & 1.241 & 0.350 \\
\hline & Total MRC at baseline ${ }^{*} \mathrm{BI}$ & -0.005 & 0.000 & 0.995 & 0.992 & 0.998 & \\
\hline \multirow[t]{2}{*}{ At 3 months in the UL } & $\mathrm{Bl}$ & 0.136 & 0.003 & 1.146 & 1.049 & 1.252 & 0.378 \\
\hline & Total UL MRC at baseline * $\mathrm{BI}$ & -0.009 & 0.001 & 0.991 & 0.986 & 0.996 & \\
\hline \multirow[t]{5}{*}{ At 3 months in the LL } & Previous stroke history & 0.684 & 0.018 & 5.051 & 1.322 & 19.303 & 0.562 \\
\hline & $\mathrm{Bl}$ & 0.348 & 0.000 & 1.417 & 1.192 & 1.684 & \\
\hline & NIHSS & -0.112 & 0.035 & 0.894 & 0.805 & 0.992 & \\
\hline & $\mathrm{BI}$ * age & -0.003 & 0.000 & 0.997 & 0.995 & 0.998 & \\
\hline & $\mathrm{BI}^{*}$ total LL MRC at baseline & -0.006 & 0.000 & 0.994 & 0.991 & 0.997 & \\
\hline At 6 months & Total MRC at baseline & -0.379 & 0.000 & 0.684 & 0.573 & 0.818 & 0.613 \\
\hline At 6 months in the UL & Total UL MRC at baseline & -0.537 & 0.000 & 0.584 & 0.442 & 0.773 & 0.592 \\
\hline At 6 months in the LL & Total LL MRC at baseline & -0.869 & 0.000 & 0.419 & 0.280 & 0.628 & 0.569 \\
\hline At 12 months & Total MRC at baseline & -0.300 & 0.000 & 0.741 & 0.647 & 0.847 & 0.577 \\
\hline At 12 months in the UL & Total UL MRC at baseline & -0.483 & 0.0000 & 0.617 & 0.484 & 0.787 & 0.597 \\
\hline \multirow[t]{3}{*}{ At 12 months in the LL } & NIHSS & 0.258 & 0.012 & 1.294 & 1.059 & 1.581 & 0.544 \\
\hline & $\mathrm{BI}$ & -0.030 & 0.016 & 0.971 & 0.948 & 0.995 & \\
\hline & $\mathrm{BI}$ * previous stroke history & 0.025 & 0.024 & 1.025 & 1.003 & 1.048 & \\
\hline
\end{tabular}

UL — upper limbs, LL — lower limbs, MRC — Medical Research Council, BI — Barthel Index, NIHSS — National Institute of Health Stroke Scale,

as spasticity is the third greatest cause of chronic pain in patients after stroke [31], in our study pain was among five QoL domains that were more affected in individuals with spasticity compared to those without. The worse QoL scores in terms of physical functioning and role limitations due to physical problems are in accordance with previous reports regarding the impact of spasticity on ADL. These findings suggest that spasticity does have a major impact on HRQoL, as well as on ADL, in stroke patients. Of note, Elovic et al. showed that botulinum toxin injections can alleviate spasticity, improve QoL, and reduce disability [32].

Even though stroke characteristics such as age, sex, side of symptoms and co-morbidities were included into analysis, mulitivariate analysis did not show any predictors of spasticity except for NIHSS score and a previous stroke. In earlier studies, young age and haemorrhagic stroke were identified as risk factors [20], but in our cohort there were only 9/121 haemorrhagic stroke patients, and this was probably responsible for the lack of significance of this possible spasticity predictor.

Severity of spasticity and degree of limb paresis were strongly associated in our study, and this is in accordance with previous reports $[6,20]$.

$\mathrm{BI}$ at discharge was identified as a significant predictor of spasticity, which seems to be important due to the wide use of this scale. In a previous study, lower sensorimotor function as identified by the Fugl-Mayer-Upper Extremity-Assessment and Motricity Index predicted spasticity at three and 12 months after stroke [7, 33]. Identifying BI and NIHSS scores as predictors of spasticity seems more relevant to routine clinical practice.

A relatively large cohort of stroke survivors with initial limb paresis, assessed prospectively by one physician so as to avoid inter-rater variability, is the major strength of our study. A deterioration in the HRQoL score in the spasticity group was also demonstrated, and this may explain why vigorous treatments are needed.

However, our study design had several limitations. Because the first follow-up assessment was after three months, the precise time when spasticity could be noticed has not been established. Also, the influence of rehabilitation and of oral antispastic medication (the efficacy of the latter having been questioned), were not analysed. In future studies, more frequent follow-up muscle tone assessments during the first month after stroke may enable optimal timing of early botulinum toxin treatment combined with a specific rehabilitation programme [34].

\section{Conclusions}

Spasticity is a relatively frequent sequel of stroke, and has major impacts on daily functioning and quality of life. Pronounced paresis, more severe disability, and stroke severity at baseline, are the most important predictors of developing spasticity in more than one third of patients. 
Ethics: Written informed consent was obtained from patients, and the present study was approved by the local ethics committee at the Medical University of Gdan'sk, Poland.

Disclosures: None

\section{References}

1. World Health Organization. The global burden of disease: 2004 update. http://www who int/healthinfo/global_burden_disease/2004_ report_update/en/index html. 2012.

2. Gorelick PB, Alter M, Deekker M. Handbook of neuroepidemiology. New York, Basel, Hongkong 1994.

3. Mayer NH. Clinicophysiologic concepts of spasticity and motor dysfunction in adults with an upper motoneuron lesion. Muscle Nerve Suppl. 1997; 6: S1-13, indexed in Pubmed: 9826979.

4. Schinwelski M, Sławek J. Prevalence of spasticity following stroke and its impact on quality of life with emphasis on disability in activities of daily living. Systematic review. Neurol Neurochir Pol. 2010; 44(4): 404-411, doi: 10.1016/s0028-3843(14)60300-5, indexed in Pubmed: 20827614.

5. Shin YI, Kim SY, Lee HIn, et al. Association Between Spasticity and Functional Impairments During the First Year After Stroke in Korea: The KOSCO Study. Am J Phys Med Rehabil. 2018; 97(8): 557-564, doi: 10.1097/PHM.0000000000000916, indexed in Pubmed: 29509548.

6. Urban PP, Wolf T, Uebele M, et al. Occurence and clinical predictors of spasticity after ischemic stroke. Stroke. 2010; 41(9): 2016-2020, doi: 10.1161/STROKEAHA.110.581991, indexed in Pubmed: 20705930.

7. Opheim A, Danielsson A, Alt Murphy M, et al. Upper-limb spasticity during the first year after stroke: stroke arm longitudinal study at the University of Gothenburg. Am J Phys Med Rehabil. 2014; 93(10): 884896, doi: 10.1097/PHM.0000000000000157, indexed in Pubmed: 25180838.

8. Milinis K, Young CA. Trajectories of Outcome in Neurological Conditions (TONiC) study. Systematic review of the influence of spasticity on quality of life in adults with chronic neurological conditions. Disabil Rehabil. 2016; 38(15): 1431-1441, doi: 10.3109/09638288.2015.1106592, indexed in Pubmed: 26713898.

9. Bohannon RW, Smith MB. Interrater reliability of a modified Ashworth scale of muscle spasticity. Phys Ther. 1987; 67(2): 206-207, doi: 10.1093/ptj/67.2.206, indexed in Pubmed: 3809245.

10. Gregson JM, Leathley MJ, Moore AP, et al. Reliability of measurements of muscle tone and muscle power in stroke patients. Age Ageing. 2000; 29(3): 223-228, doi: 10.1093/ageing/29.3.223, indexed in Pubmed: 10855904.

11. Katz RT, Rymer WZ. Spastic hypertonia: mechanisms and measurement. Arch Phys Med Rehabil. 1989; 70(2): 144-155, indexed in Pubmed: 2644919.

12. Adams HP, Davis PH, Leira EC, et al. Baseline NIH Stroke Scale score strongly predicts outcome after stroke: A report of the Trial of Org 10172 in Acute Stroke Treatment (TOAST). Neurology. 1999; 53(1): 126-131, doi: 10.1212/wnl.53.1.126, indexed in Pubmed: 10408548.

13. British Medical Research Council. Aid to the investigation of peripheral nerve injuries. In: war memorandum. HSMO. London: 1943: 1-46.

14. Kasner SE. Clinical interpretation and use of stroke scales. Lancet Neurol. 2006; 5(7): 603-612, doi: 10.1016/S1474-4422(06)704951, indexed in Pubmed: 16781990.
15. Collin C, Wade DT, Davies S, et al. The Barthel ADL Index: a reliability study. Int Disabil Stud. 1988; 10(2): 61-63, doi: 10.3109/09638288809164103, indexed in Pubmed: 3403500.

16. Tylka J, Piotrowicz R. [Quality of life questionnaire SF-36 - Polish version]. Kardiol Pol. 2009; 67(10): 1166-1169, indexed in Pubmed: 20209678.

17. Anderson C, Laubscher S, Burns R. Validation of the Short Form 36 (SF-36) health survey questionnaire among stroke patients. Stroke. 1996; 27(10): 1812-1816, doi: 10.1161/01.str.27.10.1812, indexed in Pubmed: 8841336.

18. Sommerfeld DK, Eek EUB, Svensson AK, et al. Spasticity after stroke: its occurrence and association with motor impairments and activity limitations. Stroke. 2004; 35(1): 134-139, doi: 10.1161/01. STR.0000105386.05173.5E, indexed in Pubmed: 14684785.

19. Welmer AK, von Arbin M, Widén Holmqvist L, et al. Spasticity and its association with functioning and health-related quality of life 18 months after stroke. Cerebrovasc Dis. 2006; 21(4): 247-253, doi: 10.1159/000091222, indexed in Pubmed: 16446538.

20. Lundström E, Terént A, Borg J. Prevalence of disabling spasticity 1 year after first-ever stroke. Eur J Neurol. 2008; 15(6): 533-539, doi: 10.1111/j.1468-1331.2008.02114.x, indexed in Pubmed: 18355307.

21. Watkins CL, Leathley MJ, Gregson JM, et al. Prevalence of spasticity post stroke. Clin Rehabil. 2002; 16(5): 515-522, doi: 10.1191/0269215502cr5120a, indexed in Pubmed: 12194622.

22. Leathley MJ, Gregson JM, Moore AP, et al. Predicting spasticity after stroke in those surviving to 12 months. Clin Rehabil. 2004; 18(4): 438-443, doi: 10.1191/0269215504cr727oa, indexed in Pubmed: 15180128

23. Dietz V. Human neuronal control of automatic functional movements: interaction between central programs and afferent input. Physiol Rev. 1992; 72(1): 33-69, doi: 10.1152/physrev.1992.72.1.33, indexed in Pubmed: 1731372.

24. Moura Rd, Fukujima MM, Aguiar AS, et al. Predictive factors for spasticity among ischemic stroke patients. Arq Neuropsiquiatr. 2009; 67(4): 1029-1036, doi: 10.1590/s0004-282×2009000600013, indexed in Pubmed: 20069214.

25. Kuptniratsaikul V, Kovindha A, Suethanapornkul S, et al. Long-term morbidities in stroke survivors: a prospective multicenter study of Thai stroke rehabilitation registry. BMC Geriatr. 2013; 13: 33, doi: 10.1186/1471-2318-13-33, indexed in Pubmed: 23586971.

26. Thilmann AF, Fellows SJ, Garms E. The mechanism of spastic muscle hypertonus. Variation in reflex gain over the time course of spasticity. Brain. 1991; 114 ( Pt 1A): 233-244, indexed in Pubmed: 1998884.

27. Welmer AK, Widén Holmqvist L, Sommerfeld DK. Location and severity of spasticity in the first 1-2 weeks and at 3 and 18 months after stroke. Eur J Neurol. 2010; 17(5): 720-725, doi: 10.1111/j.14681331.2009.02915.x, indexed in Pubmed: 20050897.

28. Gracies JM. Pathophysiology of spastic paresis. I: Paresis and soft tissue changes. Muscle Nerve. 2005; 31(5): 535-551, doi: 10.1002/ mus.20284, indexed in Pubmed: 15714510.

29. Oneş K, Yalçinkaya EY, Toklu BC, et al. Effects of age, gender, and cognitive, functional and motor status on functional outcomes of stroke rehabilitation. NeuroRehabilitation. 2009; 25(4): 241-249, doi: 10.3233/NRE-2009-0521, indexed in Pubmed: 20037216.

30. Mayo NE, Wood-Dauphinee S, Côté R, et al. Activity, participation, and quality of life 6 months poststroke. Arch Phys Med Rehabil. 2002; 83(8): 1035-1042, doi: 10.1053/apmr.2002.33984, indexed in Pubmed: 12161823. 
31. O'Donnell MJ, Diener HC, Sacco RL, et al. PRoFESS Investigators. Chronic pain syndromes after ischemic stroke: PRoFESS trial. Stroke. 2013; 44(5): 1238-1243, doi: 10.1161/STROKEAHA.111.671008, indexed in Pubmed: 23559265.

32. Elovic EP, Brashear A, Kaelin D, et al. Repeated treatments with botulinum toxin type a produce sustained decreases in the limitations associated with focal upper-limb poststroke spasticity for caregivers and patients. Arch Phys Med Rehabil. 2008; 89(5): 799-806, doi: 10.1016/j.apmr.2008.01.007, indexed in Pubmed: 18452724.
33. Ryu JuS, Lee JW, Lee SII, et al. Factors predictive of spasticity and their effects on motor recovery and functional outcomes in stroke patients. Top Stroke Rehabil. 2010; 17(5): 380-388, doi: 10.1310/tsr1705380, indexed in Pubmed: 21131263.

34. Fietzek UM, Kossmehl P, Schelosky L, et al. Early botulinum toxin treatment for spastic pes equinovarus--a randomized double-blind placebo-controlled study. Eur J Neurol. 2014; 21(8): 1089-1095, doi: 10.1111/ene.12381, indexed in Pubmed: 24754350. 